O Eixo e a roda, Belo Horizonte, v.24, n.1, p. 187-201, 2015

\title{
A música desconhecida de Paulo Henriques Britto
}

\section{Paulo Henriques Britto's unknown music}

\section{Eduardo Horta Nassif Veras}

Universidade Estadual de Campinas (Unicamp), Campinas, São Paulo, Brasil. eduardohnveras@gmail.com

Resumo: Este artigo propõe uma breve análise da presença da música na poética de Paulo Henriques Britto. Dialogando com a obra ensaística do poeta francês Jean-Michel Maulpoix, pretendo demonstrar que a obra do poeta carioca insere-se de maneira peculiar na discussão contemporânea acerca das heranças da tradição lírica, não podendo, portanto, ser associada de maneira direta às poéticas de matriz antilírica. Tal análise abre-se, finalmente, para uma posterior reflexão sobre o lugar de Britto na história da poesia brasileira.

Palavras-chave: poesia contemporânea; lirismo; antilirismo; Paulo Henriques Britto.

Abstract: This paper proposes a brief analysis of the presence of music in Paulo Henriques Britto's poetics. In a dialogue with the French poet Jean-Michel Maulpoix's essays, my aim is to demonstrate that the work of the "carioca" poet is inserted in the contemporary discussion about the legacy of lyric tradition and therefore cannot be directly associated with an anti-lyric poetics. This analysis finally opens up for further reflection on Britto's position in the history of Brazilian poetry.

Keywords: contemporary poetry; lyricism; anti-lyricism; Paulo Henriques Britto. 
Recebido em 21 de março de 2015. Aprovado em 28 de julho de 2015.

Des châteaux bâtis en os sort la musique inconnue.

(Arthur Rimbaud)

O que se pensa não é o que se canta.

Dificil sustentar um raciocínio com a rima atravessada na garganta. (Paulo Henriques Britto)

\section{0 adeus à música}

Geralmente associada à tradição clássica, que valoriza a construção racional do poema e, em sua retomada moderna, se opõe às noções românticas de inspiração e de expressão da subjetividade, a poética de Paulo Henriques Britto, também associada frequentemente à linhagem antilírica de nossa tradição poética, estabelece, entretanto, uma relação bastante ambivalente com alguns dos principais elementos que caracterizam o lirismo. Presente em praticamente todas as suas obras, essa ambivalência pode ser compreendida como uma espécie de problematização crítica da tradição da poesia moderna, que, como se sabe, definiu-se prioritariamente, desde Baudelaire, como uma reação à poesia confessional, isto é, como uma afirmação do caráter construtivo do discurso poético. As consequências dessa reação são conhecidas de todos: crise do verso e surgimento do verso livre; diluição da linguagem poética, anteriormente caracterizada pelo uso irrestrito de imagens; aproximação entre poesia e prosa; surgimento do poema em prosa; contaminação do discurso poético pelo discurso crítico e o fim da aliança com a música, que caracterizava a linhagem mais forte da tradição lírica ocidental até as últimas décadas do século XIX. Num certo sentido, como tentarei demonstrar adiante, a poesia de Paulo Henriques Britto se associa, ao mesmo tempo, ao prolongamento e à superação desse movimento de reação que está na base da poesia moderna ocidental e de um eixo bastante importante da tradição poética nacional, que passa pelas obras de Manuel Bandeira, Mário de Andrade, Carlos Drummond de Andrade até alcançar 
seu apogeu na obra de João Cabral de Melo Neto (Cf. COSTA LIMA, 1995) e, posteriormente, no desenvolvimento de poéticas de cunho formalista como o concretismo. Não somente a retomada de elementos musicais, tema principal deste artigo, mas também a reconsideração moderada da subjetividade, a problematização do lugar da poesia na sociedade, a incorporação de elementos das linguagens oral e popular, associadas a uma prática poética claramente construtivista fazem de Paulo Henriques Britto um poeta de difícil classificação no panorama da poesia brasileira das últimas décadas. ${ }^{1}$

O título que escolhi para este artigo se refere ao último ensaio do poeta e crítico francês Jean-Michel Maulpoix, que, por sua vez, se inspira no verso de Rimbaud que também utilizo aqui como epígrafe. No contexto da poesia contemporânea francesa, marcado pelos debates entre a tradição antipoética de Francis Ponge e Jean-Marie Gleize e a tradição neolírica, Maulpoix, tomando o partido desta última, defende um retorno crítico ao lirismo, o que passa também por uma espécie de reconsideração do diálogo com a música. Em La Musique inconnue ( $A$ Música desconhecida), ensaio publicado em 2013, Maulpoix afirma que "de diversos modos, a poesia moderna diz adeus ao canto, ao pathos, ao sujeito, à imagem..." e que "parecendo se afastar desse mundo que celebrava no passado, ela acaba se despedindo de si mesma" 2 (MAULPOIX, 2013, p. 28; tradução minha). Partindo dessa afirmação e observando mais de perto a história recente da poesia moderna, não

${ }^{1}$ É importante ressaltar que a resistência às classificações tradicionais é uma característica mais ou menos compartilhada por todo poeta merecedor do epíteto 'contemporâneo'. Essa resistência pode ser explicada pela falência dos grandes programas literários, como o modernismo e o concretismo, para citar dois exemplos ligados à literatura brasileira. $\mathrm{O}$ colapso desses modelos acabou por provocar aquilo que o crítico Marcos Siscar (2010, p. 152) chama de "cisma da poesia brasileira", definida mais especificamente como "o sintoma de um mal-estar teórico que consiste em uma indecisão quanto à natureza e à situação da poesia contemporânea". Ainda falando do caso brasileiro, essa indecisão se explicaria por uma herança bastante perceptível na obra de Paulo Henriques Britto, a saber, aquela "fundada na cisma da oposição entre a poesia concretista, semiótica, tecnológica, formalista de modo geral, e a poesia do cotidiano, a poesia que busca inspiração na língua e na cultura popular" (SISCAR, 2010, p. 153).

${ }^{2}$ De bien de façons, la poésie moderne dit adieux au chant, au pathos, au sujet, à l'image... En semblant s'éloigner de ce monde qu'elle célébrait naguère, elle en vient à se donner à elle-même son congé. 
é difícil perceber que a recusa dos poetas em manter o velho diálogo com a música - o que, em última instância, é capaz de resumir de maneira muito eficaz o que se entende por antilirismo - coincide quase sempre com o mal-estar vivenciado pelos mesmos poetas a respeito da validade de seu próprio discurso. Em outras palavras, pretendo sugerir que o "adeus à música" sobre o qual fala Maulpoix apresenta diversos pontos de contato com o problema da crise da poesia moderna, que pode ser resumido pela inquietação vivenciada pelos próprios poetas e pela incorporação poética da reflexão sobre o lugar e a essência do discurso da poesia na modernidade. ${ }^{3}$

\section{A poesia-crítica}

Todas essas questões estão presentes, de maneira mais ou menos clara, na poesia de Paulo Henriques Britto. E é justamente aqui que reside sua grande especificidade em relação à obra de Maulpoix, que tomo como uma referência, entre outras possíveis, da renovação lírica na poesia contemporânea. O diálogo entre poesia e crítica, a recusa e a retomada da subjetividade, da música e do lirismo não são teorizados fora do contexto poético, mas dramatizados no próprio poema pelo poeta brasileiro. Começo me atendo, desde já, ao problema da convergência entre poesia e crítica na obra de Britto. Para tanto, considere-se o poema de abertura do livro Tarde (2007, p. 9):

\footnotetext{
"No poema moderno, é sempre nítida

uma tensão entre a necessidade

de exprimir-se uma subjetividade

numa personalíssima voz lírica

e, de outro lado, a consciência crítica

de um sujeito que se inventa e evade,

ao mesmo tempo ressaltando o que há de

falso em si próprio - uma postura cínica,
}

\footnotetext{
${ }^{3}$ Evidentemente, trata-se aqui de uma concepção de poesia estreitamente ligada à noção de lirismo. Para Maulpoix (2013, p. 95), "a música (...) é a alma da poesia: aquilo que nela permanece de inatingível, difuso e irredutível à linguagem articulada" (tradução minha). La musique, (...), est l'âme de la poésie : ce qu'il demeure en elle d'insasissable, de diffus et d'irréductible au langage articulé. A respeito da crise da poesia, cf. Siscar (2010).
} 
talvez, porém honesta, pois de boa-

fé o autor desconstrói seu artifício, desmistifica-se para o "leitor-

irmão..." hm. Pode ser. Mas o Pessoa, em doze heptassílabos, já disse o mesmo - não, disse mais - muito melhor.

Esse poema encena um dos principais paradoxos da poesia de Britto: a simulação do discurso crítico, de tonalidade prosaica, dissertativa, em versos rigorosamente construídos. A tensão entre o caráter referencial da linguagem e o ritmo dos decassílabos que compõem o soneto encontra respaldo no plano do conteúdo, onde se afirma textualmente aquilo que o próprio poema materializa formalmente. Mais que levantar a discussão a respeito do fingimento poético, e, portanto do caráter construtivo da criação poética moderna, esse poema dramatiza a convergência entre os discursos crítico e poético na modernidade. Após simular uma longa citação pretensamente extraída de um texto teórico, que só se encerra no início do último terceto, o poeta reassume a voz do poema para dizer que Fernando Pessoa fora capaz, em seu famoso poema "Autopsicografia", de dizer melhor a mesma coisa. Muito interessante observar a tensão que se estabelece no poema, que se apropria do discurso crítico - que também participa do jogo do "fingimento" - sobre a poesia para fazer o elogio de um poeta, e, portanto da própria poesia, através de uma linguagem ao mesmo tempo clara e poeticamente estruturada. Mais interessante ainda é perceber que Britto realiza em seu poema os dois lados da "tensão" sobre a qual discorre: ao mesmo tempo que coloca em cena a discussão acerca da poesia moderna, apropriando-se poeticamente dela, o que já configura por si só a tensão entre os dois tipos de discurso, ele o faz de maneira particular, dando vazão àquilo que seu próprio poema define como uma "personalíssima voz lírica". Em seu último ensaio, Maulpoix $(2013$, p. 69 - 87) chama a atenção diversas vezes para o tema da voz como um elemento fundamental para a reflexão sobre a essência do discurso poético. Segundo ele, "o poema se impõe e se imprime como voz no ouvido e na página: como se fosse uma voz que subisse da página. Uma voz que tomasse corpo e se colocasse de pé" ${ }^{4}$ (p. 72; tradução

${ }^{4}$ Le poème s'impose et s'imprime comme voix dans l'oreille et sur la page : comme si c'était une voix qui montait de la page. Une voix que prenait corps et s'y mettait debout. 
minha). Associada ao corpo e, claro, ao canto, a voz se define como "personalíssima", isto é, como manifestação lírica em todos os sentidos - por sua dupla relação com a música e com a subjetividade.

Na poesia de Britto, porém, a presença dessa voz que dá corpo e personalidade à linguagem é frequentemente assombrada pelo questionamento da consciência, num jogo de constante oscilação entre a performance e a análise, entre a poesia e a crítica, que anuncia outros dois tópicos de sua poética também caracterizados por antíteses. Nesse sentido, é possível dizer que a interpretação que proponho neste artigo se baseia na equivalência entre três pares opostos como chave de leitura para a poesia de Britto. O primeiro deles, apresentado acima, é composto pela tensão entre os discursos poético e crítico, metaforizados pelas imagens da voz e do corpo. Os outros dois, que serão analisados a seguir, podem ser considerados como desdobramentos do primeiro. No que diz respeito ao problema do qual se ocupa prioritariamente este artigo, a antítese poesia versus música se traduz na oposição entre o som e o sentido, entre a materialidade semiótica do discurso poético e o caráter incontornavelmente mimético de toda linguagem verbal. No plano mais amplo da teoria da poesia moderna, essas duas antíteses dão origem a uma terceira, a antítese entre a busca pela especificidade do discurso poético e sua vocação comunitária, isto é, sua capacidade de produzir sentido coletivo, de se comunicar. Essas três antíteses se apresentam como um problema central na história da poesia moderna e são absorvidas por Britto como elementos de uma tensão insolúvel, a ponto de fundar uma espécie de concepção oximórica da poesia, como tentarei mostrar também adiante. Essa tensão parece se explicar em função da própria concepção de sujeito colocada em cena pelo poeta, o que explica também sua concepção moderada de lirismo e sua relação com o pensamento crítico. Para o poeta, conforme se pode ler no poema "Poética prática", publicado em Formas do nada: "O corpo não é preciso, e o espírito é impreciso: / eu não é um nem outro" (2012, p. 18), isto é, o sujeito se define justamente por sua indecisão entre o material e o imaterial, entre as sensações e as ideias. E a esse sujeito, como mostrarei a seguir, corresponde uma poesia que também oscila entre o significante e o significado, entre a imagem e a crítica, entre o som e o sentido:

Anda inconveniente a tal da poesia

A significar?

Nada como um bom significante vazio

Para abolir o azar. (2012, p. 18) 


\title{
3 A música ingrata
}

Há algo de limitado ou constrangido no lirismo de Paulo Henriques Britto. Sua música duplamente desconhecida - da crítica, que tradicionalmente $\mathrm{o}$ associa à tradição antilírica, e também da própria tradição, pois se caracteriza pela idiossincrasia, pela alteridade total em relação à música romântica, retumbante, apoteótica e mística - parece guardar algo de involuntário, insinuando-se no poema à revelia do próprio poeta, se nos permitirmos acreditar no que ele mesmo escreve sobre o assunto, em um poema de Formas do nada (2012, p. 15), seu último livro de poemas:

\author{
Música ingrata, música orgulhosa, \\ capaz de se enquistar nos intestinos \\ mais íntimos da mais agreste prosa \\ em cálculos duros e cristalinos, \\ à revelia de quem desejava \\ um rio de sentidos retilíneos, \\ colocando aqui e ali uma trava, \\ revelando aquilo que nada tem \\ de relevante, turvando o que estava \\ mais límpido, enviesando o que ninguém \\ vai desvirar, desviando da rota \\ o que não devia nunca ir além \\ do rotineiro, música que brota \\ onde a palavra era para ser mais bruta.
}

Nesse poema, a música aparece como manifestação de algo que tem vida própria e que ameaça o controle racional da produção literária. Ao contrário do que se observa na maioria das poéticas de matriz romântica, para as quais a música associa-se à fluidez da imaginação, a música se define, aqui, como "cálculos duros e cristalinos" que interrompem o fluxo do desejado "rio de sentidos retilíneos". Em oposição à imagem da retidão, ela aparece também como uma trava que turva, que enviesa e desvia o caminho da poesia para além do rotineiro. Mais uma vez, interessa observar o quanto esse poema é capaz 
de dramatizar o problema da relação entre o som e o sentido ao mesmo tempo que ele o aborda fazendo uso de uma linguagem que faz fronteira com a prosa, mas sem abrir mão dos recursos líricos. Como na maioria dos poemas de Britto, os quatorze versos desse poema caracterizam-se por uma linguagem aparentemente dissertativa, deixando transparecer, ao mesmo tempo, uma preocupação bastante refinada com a melopeia - atente-se, por exemplo, para as aliterações em ' $t$ ' $e$ ' $d$ ', consoantes dentais que percorrem praticamente todo o poema, contribuindo para a concretização sonora da imagem da dureza e da aspereza dos "cálculos duros e cristalinos".

Esse poema mostra, mais uma vez, que a síntese entre a comunicabilidade e a musicalidade, entre o som e o sentido, se dá de maneira tensa na poesia de Britto, uma limitando linguística e semioticamente a outra. Aqui, cabe lembrar a definição de poesia "como uma hesitação prolongada entre o som e o sentido" " proposta por Valéry e retomada por Maulpoix (2013, p. 81; tradução minha). No caso de Paulo Henriques Britto, não posso deixar de observar que essa tensão também pode ser entendida como fruto de uma encenação poética, o que faz sua poesia mergulhar fundo em direção às raízes fundamentais da poesia moderna, como o próprio poeta sugere no poema inaugural de Tarde. ${ }^{7}$ É preciso lembrar que a queixa dirigida pelo poeta à "Música ingrata" se realiza no âmbito de um poema construído especialmente para tanto. Nesse sentido, a ideia de um lirismo à revelia mostra-se duplamente rica: por um lado, somos levados a perceber, ao longo da leitura da obra do poeta, que seu discurso aparentemente antilírico não se sustenta

\footnotetext{
${ }^{5}$ Música ingrata, música orgulhosa, / capaz de se enquistar nos intestinos / mais íntimos da mais agreste prosa // em cálculos duros e cristalinos, / à revelia de quem desejava / um rio de sentidos retilíneos, // colocando aqui e ali uma trava, / revelando aquilo que nada tem / de relevante, turvando o que estava // mais límpido, enviesando o que ninguém / vai desvirar, desviando da rota / o que não devia nunca ir além // do rotineiro, música que brota /onde a palavra era para ser mais bruta.

6"une hésitation prolongée entre le son et le sens"

${ }^{7}$ A adesão de Paulo Henriques Britto à noção moderna de "fingimento poético" é atestada diversas vezes. Num poema do livro Formas do nada intitulado "Canção", o poeta afirma: "Fingir não é nada difícil / quando a própria realidade / é, de todas as hipóteses, / a que é mais indesejada." (2012, p. 54). Já em "Ecce homo", do mesmo livro, o vemos ressaltar a relação entre o fingimento e o trabalho poético: "Não ser quem não se é é coisa trabalhosa. / Exige a disciplina austera e rigorosa / de quem, achando pouco simplesmente ser, / requer o luxo adicional de parecer." (2012, p. 38).
} 
plenamente, pois a música se insinua constantemente em seus versos. Por outro lado, vemos o próprio poeta assumir sua "incapacidade" de extirpar os resquícios de musicalidade que penetram nos interstícios de sua poesia. Por fim, temos uma demonstração de consciência crítica por parte do poeta, que dramatiza, em um poema marcadamente musical, a coincidência absoluta entre o fracasso de seu discurso antilírico e a realização poética de alguma coisa que não merece mais esse nome. Em outras palavras, quero dizer que a presença da "Música ingrata" em sua poesia deve ser interpretada, ao mesmo tempo, como uma experiência de fracasso e de adesão a um tipo de lirismo que não coincide mais com a tradição romântica, e que chamarei aqui de lirismo em surdina, em referência ao seu caráter tímido e autocontrolado. Trata-se de algo novo, a meu ver, uma espécie de música desconhecida ${ }^{8}$ Essa adesão ao mesmo tempo deliberada, componente de uma poética construtiva, calculada, e resultante de uma derrota, do fracasso de determinado discurso sobre a poesia que vigorou no Brasil e no mundo ao longo das últimas décadas - realiza uma espécie de última volta no parafuso em direção à hiperconcentração do discurso poético, isto é, à afirmação da poesia por ela mesma, à afirmação da poesia como uma linguagem e uma experiência irredutíveis. Trata-se de uma ideia bastante cara ao neolirismo

\footnotetext{
${ }^{8} \mathrm{~A}$ reflexão sobre a música e sua relação com a poesia, bem como o emprego de metáforas musicais são procedimentos frequentes na poesia de Paulo Henriques Britto. Ao contrário do que se via no final do século XIX, momento em que a poesia simbolista, em especial, elege a música como modelo para a criação poética a ponto de defender a fusão entre as duas artes, conforme o ideal wagneriano, vemos o poeta brasileiro defender justamente o contrário, a alteridade entre as duas linguagens: "Dúvida, porém, não há: língua é língua, / e clavicórdio, clavicórdio é. / Assim como a canção do clavicórdio // não é a mesma música do vento, / e o vento não é pássaro ou cigarra / que canta, sem que o saiba, o verão, // palavra é mais que o bajular do vento, / que o monocórdio de cigarra ou pássaro, / mais que o mais sábio clavicórdio. // Mais mágica que música, afinal, /a inflacionar o mundo de fantasmas. / Desses fantasmas se faz o real." (2007, p. 86). Necessariamente associada à significação, ao sentido - e não apenas aos sentidos - a poesia - ou a canção - não coincide com o clavicórdio, que era empregado, aliás, no âmbito da música barroca, principalmente como instrumento de acompanhamento. Contudo, da mesma maneira como se viu no poema sobre a "Música ingrata", percebe-se claramente, neste poema, a insinuação de recursos sonoros e fanopaicos que venho buscando associar à tradição lírica. Em outras palavras, tem-se aqui mais um exemplar de poema musical à sua própria revelia.
} 
de Maulpoix, para quem a música desconhecida da poesia moderna se associa exatamente à intransitividade que as duas manifestações artísticas compartilham entre si. ${ }^{9}$ No caso de Paulo Henriques Britto, a busca pela especificidade do discurso poético não se separa da reflexão sobre a própria poesia, como se pode verificar nos muitos poemas metapoéticos presentes em sua obra, e da preocupação do poeta em conciliar a sensação (palavra que resume, a meu ver, muitos dos postulados de Maulpoix sobre o discurso lírico) e a ideia, conforme fica claro em poemas como este, intitulado "Ossos do ofício" e publicado no livro Tarde (2007, p. 44):

O que se pensa não é o que se canta.

Difícil sustentar um raciocínio

com a rima atravessada na garganta.

Mesmo o maior esforço não adianta:

da sensação à ideia há um declínio,

e o que se pensa não é o que se canta.

Difícil, sim. E é por isso que encanta.

Há que sentir - e aí está o fascínio -

com a rima atravessada na garganta.

Apenas isso justifica tanta

dedicação, tanto autodomínio,

se o que se pensa não é o que se canta,

mesmo porque (constatação que espanta

qualquer espírito mais apolíneo)

a rima atravessada na garganta

é o trambolho que menos se agiganta

nesse percurso mais retilíneo,

ao fim do qual se pensa o que se canta,

depois que a rima atravessa a garganta.

\footnotetext{
${ }^{9}$ Mais uma vez se remetando ao tema da voz, Maulpoix (2013, p. 87) fala de um modelo de poesia compartilhado por Valéry e Bonnefoy (este último, importante referência para o neolirismo francês) definido como "puro gasto (dépense) da voz, constituindo em si uma experiência radical da linguagem e não querendo se colocar a serviço de nada que a preexista (...)" (tradução minha). Ce modèle du poème comme pure dépense de la voix, constituant en soi une expérience radicale du langage et ne voulant se mettre au service de rien que lui préexiste (...).
} 
O poema deixa claro que a conciliação entre o pensamento e a sensação, entre as ideias e a forma, é fruto de "dedicação" e de "autodomínio". A imagem da "rima atravessada na garganta", que percorre todo o poema, não é muito diferente da imagem da "música ingrata" definida como "cálculos duros e cristalinos". Recurso poético ligado à tradição lírica, a rima se apresenta de forma bastante ambivalente nesse poema de Britto: ao mesmo tempo que aparece associada a algo que constrange as cordas vocais, isto é, a algo que impede a fluência da voz, ela é vista também como uma espécie de pedra no meio do caminho, como um "trambolho" pelo qual, entretanto, se deve passar necessariamente no processo de criação poética, que se realiza na coincidência final entre "o que se pensa" e "o que se canta", ou seja, na conservação burilada do elemento musical. Assim como a "música ingrata", a "rima atravessada na garganta" representa a matéria prima incontornável na qual o poeta trabalha, o protótipo sensível que dará lugar à comunicação poética, que se estabelece justamente na fronteira entre a sensação e a ideia.

\section{A música desconhecida ou o canto oximórico}

Pode parecer estranho falar em intransitividade quando se trata de analisar a obra de um poeta tão preocupado em se aproximar da prosa e em reafimar o caráter comunicativo da linguagem poética. ${ }^{10}$ Acredito que uma parte considerável da poética de Paulo Henriques Britto explica-se justamente por esse aparente paradoxo, pela tensão existente entre as funções poética e referencial da linguagem. ${ }^{11} \mathrm{Na}$ verdade, trata-se muito

\footnotetext{
${ }^{10}$ Esse problema nos remete diretamente a uma das discussões fundamentais da tradicão da poesia moderna. Mallarmé se ocupou dele em suas Divagations (cf. 2003, p. 259), dando origem, posteriormente, a uma série de teorias a respeito da essência da linguagem poética e de sua relação com a linguagem comum. A ideia de intransitividade se associaria, no contexto dessa discussão, a uma concepção de poesia avessa à representação e, portanto, à comunicação, conforme a leitura que boa parte das vanguardas poéticas fizeram de Mallarmé ao longo do século XX. De certa forma, a ideia de uma "intransitividade comunicativa", aparentemente paradoxal, sugere uma espécie de reconciliação entre as linguagens poética e comunicativa, reafirmando, ao mesmo tempo, a especificidade e a vocação comunitária do discurso poético, conforme as leituras mais recentes que têm sido feitas da teoria da linguagem de Mallarmé. Cf. a esse respeito os escritos de Bertrand Marchal e de Marcos Siscar sobre o poeta francês. ${ }^{11}$ Diversas passagens da obra do poeta poderiam ser citadas aqui para exemplificar
} 
mais da superação da velha dicotomia - lirismo versus antilirismo - que somente de um paradoxo puro e simples. Em outras palavras, é possível dizer que a poesia de Britto se aproxima, em alguns aspectos, daquilo que Maulpoix (2009) chama de lirismo crítico. A meu ver, essa noção dialoga triplamente com a produção do poeta brasileiro da seguinte forma. Em primeiro lugar, pelo fato de o lirismo crítico se caracterizar justamente pelo reconhecimento e, claro, pela dramatização poética dos limites da poesia. Para Maulpoix (2009, p. 10), a noção de lirismo deve ser compreendida como uma espécie de referência em função da qual os poetas são levados a se situar, seja contra ou a favor. Outro elemento importante presente no lirismo crítico e que dialoga também com a poética de Britto refere-se à preocupação com a especificidade do discurso poético. Para Maulpoix (2009, p. 11), essa especificidade se encontra no trabalho com a língua: "trata-se de lembrar aquilo que (...) torna [a poesia] insubstituível: sua atenção fervorosa à língua, sua faculdade de encantamento, seu poder de ligação, e a intensidade da reflexão que ela induz a respeito da palavra humana" 12 (tradução minha). E em terceiro lugar, completando o tripé do lirismo crítico de Britto, cabe dizer que a afirmação do caráter insubstituível da poesia não se dá pela recusa da linguagem comunitária, mas, ao contrário, por sua incorporação. "Ao invés de evadir rumo às altitudes azuis, ele [o poeta]

esse parodoxo da comunicação poética, que se realiza justamente na fronteira tensa entre a intransitividade da poesia (tanto no sentido social quanto no sentido linguístico, isto é, como uma linguagem caracterizada ao mesmo tempo pela marginalidade em relação a outros discursos (da ciência, da imprensa, do cinema, do romance, das humanidades...) e pela autorreferencialidade linguística, pela tendência do discurso poético (especialmente aquele que se desenvolve ao longo do século XX) de tomar a si próprio como alvo, como numa espécie de "Diário de viagem sem viagem /ou carta sem nenhum destinatário: /palavras que, no máximo, interagem /com outras palavras do dicionário", conforme escreve o poeta num poema de Tarde (2007), que prossegue da seguinte maneira: "um escrever que é verbo intransitivo / que se conjuga numa só pessoa. / Um texto reduzido a substantivo / menos que abstrato: se nem mesmo soa, // como haveria de querer dizer /alguma coisa que valesse o vão /e duro esforço de fazer sentido? // Por outro lado, a coisa dá prazer. / Dá uma formidável sensação / (mesmo que falsa) de estar sendo ouvido."

${ }^{12}$ Il $s$ 'agit de rappeler ce qui la rend irremplaçable: son attention fervente à la langue, sa faculté d'enchantement, son pouvoir de liaison, et l'intensité de la réflexion qu'elle induit à propos de la parole humaine. 
permanece no interior da comunidade dos homens" ${ }^{13}$, escreve Maulpoix (2009, p. 12; tradução minha). Esses três elementos componentes do lirismo crítico são perfeitamente identificáveis na poética do autor de Macau. Na abertura deste último livro, Britto (2003, p. 9) manifesta sua preocupação com o caráter excêntrico do discurso poético, a ponto de associá-lo, inicialmente, a uma experiência ridícula, mas terminando por fazer o elogio de sua especificidade, não por acaso, fazendo uso de uma figura como o oxímoro:

Há maneiras mais fáceis de se expor ao ridículo, que não requerem prática, oficina, suor. Maneiras mais simpáticas de pagar mico e dizer olha eu aqui, sou único, me amem por favor.

Porém há quem se preste a esse papel esdrúxulo, como há quem não se vexe de ler e decifrar essas palavras bestas estrebuchando inúteis, cágados com as quatro patas viradas para o ar.

Então essa fala esquisita, aparentemente anárquica, de repente é mais que isso, é uma voz, talvez, do outro lado da linha formigando de estática, dizendo algo mais que testando, testando, um dois três

câmbio? Quem sabe esses cascos invertidos, incapazes de reassumir a posição natural, não são na verdade uma outra forma de vida, tipo um ramo alternativo do reino animal?

Nos quartetos iniciais desse poema, já se anunciam alguns dos temas mais caros à poética de Britto. Além da questão da estranheza e mesmo do caráter ridículo do discurso poético, perfeitamente identificável na bela metáfora dos "cágados com as quatro patas viradas pro ar", salta aos olhos a preocupação do poeta com a construção e com a recepção racional desse tipo de discurso. No plano da produção, Britto fala em "prática", "oficina" e "suor", tópicos celebrados pelas poéticas de matriz clássica. Já no plano da

\footnotetext{
${ }^{13}$ Au lieu de s'évader vers les altitudes bleues, il demeure à l'intérieur de la communauté des hommes.
} 
recepção, destaca-se a aproximação entre "ler" e "decifrar", o que adianta uma das conclusões do poema, que acaba por afirmar o caráter comunicativo da linguagem poética, indissociável de sua excentricidade bizarra.

É interessante observar que os quartetos finais estabelecem uma mudança de tom em relação ao início do poema. $\mathrm{O}$ que fora inicialmente caracterizado como "ridículo" e "esdrúxulo", agora aparece definido como uma "outra forma de vida", como uma "voz" "dizendo algo mais que testando, testando, um dois três, câmbio?", isto é, uma voz que comunica, que produz sentido, para além da intransitividade fática, para além da autorreferencialidade. Não nos esqueçamos, porém, do fato de que o poema encerra-se com uma interrogação e de que ao longo de todos os versos prevalece uma visão, digamos, paradoxal ou mesmo oximórica da experiência poética - "ler e decifrar" "essas palavras bestas estrebuchando inúteis"; "cágados com as quatro patas viradas pro ar"; "formigando de estática"; "cascos invertidos". Uma linguagem que "formiga de estática" é uma "fala esquisita", espremida entre o absurdo - o som e a fúria - e o desejo de comunicar. E só assim pode-se voltar a falar em intransitividade, como sinônimo de especificidade, excentricidade, como característica de algo que não exige complemento, que não deve sua existência a nada exterior, como algo "insubstituível", como quer Maulpoix.

A música desconhecida de Paulo Henriques Britto se manifesta, no aparente paradoxo de sua intransitividade comunicativa, como uma espécie de canto mundano, ${ }^{14}$ prosaico e autocrítico. A encenação do retorno involuntário da música - associada a "cálculos duros e cristalinos" - nada mais é do que a afirmação da voz particularísima de um poeta enraizado no seu tempo, o tempo da crise da poesia, momento em que os poetas são chamados, mais do que nunca, a refletir sobre a essência e sobre a validade de seu próprio discurso. Não por acaso, esse canto oximórico da falência do canto deixa escapar essa "música que brota / onde a palavra era para ser mais bruta". A despeito do esforço de limpidez e depuração poética encenado pelo poeta - ou talvez em função dele, dependendo da interpretação -, uma música, ainda que mínima, em surdina, insinua-se constantemente nos poemas de Paulo Henriques Britto. Uma "música reduzida ao mais simples" ${ }^{15}$, como escreve Maulpoix em um de seus poemas. A música de um poeta que não pode deixar de ser lírico,

\footnotetext{
${ }^{14}$ Parafraseando o título de um livro do poeta suíço Philippe Jacottet - Chants d'en bas - citado por Maulpoix (2009, p. 11).

${ }^{15}$ Une musique réduite au plus simple. Verso retirado de um poema em prosa sem título, publicado no livro L'instinct du ciel, de 2000.
} 
ainda que à sua revelia. Deliberada ou não, essa abertura para a música e para o lirismo contribui para situar a obra do poeta carioca num tempo outro da história da poesia brasileira que aquele marcado pela dicotomia entre o formalismo e a informalidade, isto é, pela disputa de espaço entre as poéticas ligadas ao concretismo, de um lado, e aquelas ligadas à poesia marginal ou à poesia do cotidiano, do outro. E para além das classificações regionais, mostra o quanto sua poesia é capaz de dialogar em altíssimo nível com as questões mais sensíveis à história da poesia moderna ocidental.

\section{Referências}

BRITTO, Paulo Henriques. Macau. São Paulo: Companhia das Letras, 2003.

BRITTO, Paulo Henriques. Tarde. São Paulo: Companhia das Letras, 2007.

BRITTO, Paulo Henriques. Formas do nada. São Paulo: Companhia das Letras, 2012.

COSTA LIMA, Luiz. Lira e antilira. Mário, Drummond, Cabral. $2^{\mathrm{a}}$ ed. revista. Rio de Janeiro: Topbooks, 1995.

MALLARMÉ, Stéphane. Igitur. Divagations. Un Coup de dés. Édition de Marchal Bertrand. Paris: Gallimard, 2003.

MAULPOIX, Jean-Michel. Pour un lyrisme critique. Paris: José Corti, 2009.

MAULPOIX, Jean-Michel. La Musique inconnue. Paris: Éditions Corti, 2013.

MAULPOIX, Jean-Michel. L'instinct du ciel. Paris: Mercure de France, 2000.

SISCAR, Marcos. Poesia e crise: ensaios sobre a "crise da poesia" como topos da modernidade. Campinas: Editora da Unicamp, 2010. 
